\title{
Glass based Additives for Enhancement of PPCP Properties
}

\author{
M. Yeshwanth ${ }^{1}$, Kosaraju Srinivas ${ }^{2}$, KSN Murthy ${ }^{3}$, M. Jagadish ${ }^{4}$ \\ Research \& Analysis, Amara Raja Batteries Ltd, Karakambadi, Tirupathi. Pin -517520
}

\begin{abstract}
Blending process is the most sought method for creating high performance materials namely composite materials. Such composite materials exhibit improved properties (ex: mechanical, thermal, chemical properties etc.) which can be attributed to the stability of the morphology of the base material by addition of additives. This work discusses the blending process and performance of glass based additives (Glass Fiber and Glass Bubble) in PPCP. The trails were done by blending i.e. Short Glass fiber (SGF) with PPCP and Glass bubble (GB) with PPCP in different percentages. After due testing of these blends, the performance was compared and chosen one best formulation from both GF and GB materials. These both additives were again mixed with PPCP and made as a single formulation with slight fine tuning. By this, there observed transition in material properties from a moderate resilient nature to brittle nature giving raise to enhancement of mechanical properties and a control on density of material.
\end{abstract}

Keywords: Polypropylene co-polymer, short Glass Fiber PPCP (SGFPP), Glass Bubble (GB) material and Blending.

\section{Introduction}

PPCP (Impact Copolymer) is the well-known and widely used material for manufacturing a variety of industrial and home products because of its cost to strength comparison, easy processability and chemical properties. However, these advantages are masked by disadvantages like moderate tensile strength, low impact strength, shrinkage issues and high thermal expansion. These disadvantages can be improved by blending with other additives or materials like talc [1,2], calcium carbonate [3,4], calcium stearate [5], polyurethane [3] etc.

The other option is to choose other polymeric materials like ABS, PPO, PC etc. These materials have very good mechanical properties but are costlier than PPCP. So as mentioned above, one of the ways of cost controlling is by blending with other "additives and fillers" in certain dosage till desired properties are obtained.

Additives or fillers are like a flavor that tweaks the material properties depending on the quantity of additives added. By the addition of these, the changes in structure take place and show the behavior of the additives in the base material properties. Each additive has its own feature which boosts certain properties of the base material. But there are some back logs by use of additives i.e. increase in density and effecting the properties that are inversely proportional to the additive property. In one of the studies by B.V Lingesh [6] infer the improvement of properties by different additives but there is a slight gap i.e. the density is high resulting in a high density composite material. In the other study by Divakar $\mathrm{H}$ [7], ABS with GF material has been tried. Though the composite material has shown good improvements, the gap is again the density and the cost of ABS material has gone up. In some applications, where in the requirement for very high mechanical properties are not required and require low density. One can adopt PPCP based composite material.

The additives which are selected have to be in such a way that they should not affect other properties of the virgin
PPCP material while enhancing the target properties.

PP is one of the best materials for making composites with additives or fillers. Likewise, glass based additives have been chosen to enhance the performance of PPCP. And the additives selected are short Glass Fiber PPCP (SGFPP) and glass bubble (GB) powder. Short GF enhances the mechanical properties and GB material controls the density. The GB powder is made available as granular form by mixing in PPCP and SGFPP (70:30) materials are available as blended materials.

Table 1: General properties of PPCP are as follows according to ASTM standards

\begin{tabular}{|c|l|c|c|}
\hline S. No & \multicolumn{1}{|c|}{ Parameter } & UOM & Specification \\
\hline 1 & MFI & $\mathrm{gm} / 10 \mathrm{~min}$ & 7 to 12 \\
\hline 2 & Density & $\mathrm{gm} / \mathrm{cc}$ & $0.9 \pm 0.05$ \\
\hline 3 & $\begin{array}{l}\text { Tensile Strength at Yield } \\
50 \mathrm{~mm} / \mathrm{min}\end{array}$ & $\mathrm{Kg} / \mathrm{cm} 2$ & Min 225 \\
\hline 4 & $\begin{array}{l}\text { Izod Impact Resistance } \\
\text { (V - Notch ) }\end{array}$ & $\mathrm{Kg} . \mathrm{cm} / \mathrm{cm}$ & 7.5 to 20 \\
\hline 5 & Flexural Modulus & $\mathrm{Kg} / \mathrm{cm} 2$ & Min 9500 \\
\hline 6 & HDT & ${ }^{\circ} \mathrm{C}$ & Min 95 \\
\hline
\end{tabular}

\section{Materials \& Specimen's Preparation}

The composite materials used for the trails were compounded as per the defined percentages and extruded and then made as specimens according to the ASTM standards.

Table 2: The following are the materials used.

\begin{tabular}{|c|c|c|}
\hline S. No & Materials & Type \\
\hline 1 & PPCP & Base material \\
\hline 2 & Short GF PPCP $(30 \%$ GF $)$ & Additive \\
\hline 3 & Maleic anhydrate grafted PP & Compatibilizer \\
\hline 4 & GB granules & Additive \\
\hline
\end{tabular}

The GF material used in this study is a SGFPP material blended in PPCP in 30: 70 ratios. The density of the material is $1.54 \mathrm{gm} / \mathrm{cc}$. 


\section{International Journal of Science and Research (IJSR) \\ ISSN (Online): 2319-7064 \\ Index Copernicus Value (2013): 6.14 | Impact Factor (2015): 6.391}

The GB material studied here is in granular form and post blended with PPCP. In experiment this additive is mixed again with PPCP in different percentages. It is having the density of $0.60 \mathrm{gm}$. $/ \mathrm{cm} 3$. This material is compounded directly with PPCP in the injection molding machine.

In this experimentation process, different equipment's were utilized to make the composite material and to conduct the tests for getting the results.

1)Digital density meter: Essae Vibra is the supplier and is the instrument used to check the density of the granules studies.

2)UTM machine: DAK systems Inc. 10kn machine was used for conducting tensile strength and flexural modulus.

3)Tensile strength: The parameters fixed for tensile strength for testing are at a load of $100 \mathrm{~kg}$ load cell at $5 \mathrm{~cm} / \mathrm{min}$.

4)Flexural modulus: Parameters fixed for doing flexural modulus test are $1000 \mathrm{~kg}$ load cell at a speed of $1 \mathrm{~cm} / \mathrm{min}$.

5)Izod impact testing: International equipment is the manufacturer and specimens were taken according to the ASTM standard ASTM D256 and conducted the test.

6)Extruder machine: Lab level twin screw extruder supplied by KraussMaffei Berstorff (Model: ZE UTXi laboratory extruder) was used for the production of SGFPP material.

\subsection{Tests done under ASTM standards are as follows:}

Mechanical properties [8] were tested and the specimens are made as per ASTM standard in injection molding machine and is conditioned for 2 days, prior to subjecting to the test.

Table 3: ASTM standards for the following tests

\begin{tabular}{|c|c|c|c|}
\hline SL.No & Test & ASTM standard & Specimen dimension \\
\hline 1 & Density & ASTM D 792-86 & Granules \\
\hline 2 & Tensile strength & ASTM D638 & 165 X 19 X 3.2 \\
\hline 3 & $\begin{array}{c}\text { Izod impact } \\
\text { strength }\end{array}$ & ASTM D 256 & 64 X 12.7 X 3.2 \\
\hline 4 & Flexural modulus & ASTM D 790 & 125 X12.7 X 3.2 \\
\hline
\end{tabular}

\section{Results \& Discussion}

\subsection{SGF PPCP Material}

As we know the Poly propylene possess $40 \%$ amorphous and $60 \%$ crystalline structure. If the amorphous nature is increased by any additive, brittleness increases that leads to the improvement of tensile strength [9]. But certain disadvantages like high density and low impact strength are need to be addressed while doing so.

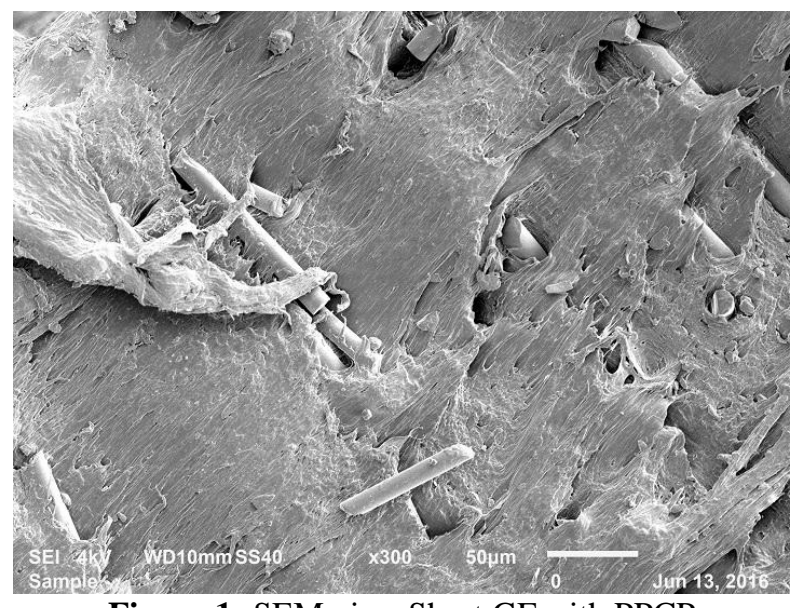

Figure 1: SEM view Short GF with PPCP

By using SGF material in PPCP, amorphous structure of material increases, as the SGF material is an amorphous material. The mechanical properties of PPCP can be improved based on the dosage added. Indeed, SGF doped polymers composite materials are presently used in some of the product applications as a replacement of aluminum, steel and wood. Even the weight reduction can also be observed compared to the metals.

The short glass fibrous material used in the present study is in the diameter of range of 3 to $20 \mu \mathrm{m}$.Each of the pellet length is around 1.5 to $2 \mathrm{~mm}$. The effectiveness of improvement depends on the adhesion between the SGF material and base material. This challenge was overcome by adding compatibilizer like maleic an-hydrate. When SGF is mixed with Polypropylene, SGF act as a high load carrying element and thereby improvise the material performance. This composite material can be recycled and reused.

\subsubsection{SGF PPCP material formulation}

This was done as a defined formulation and blended in extrusion machine.

Table 4: The following table shows the compounding percentages and process followed

\begin{tabular}{|c|c|c|c|}
\hline S1.No & Materials formulated & $\begin{array}{c}\text { Percentage of material } \\
\text { composition (For } \\
100 \%)\end{array}$ & $\begin{array}{c}\text { Process } \\
\text { followed }\end{array}$ \\
\hline 1 & $\begin{array}{c}\text { PPCP +SGFPPC + } \\
\text { Maleic an hydrate } \\
\text { grafted PP }\end{array}$ & $78+17+5$ & $\begin{array}{c}\text { Extrusion at } \\
250^{\circ} \mathrm{c}\end{array}$ \\
\hline 2 & $\begin{array}{c}\text { PPCP +SGFPCP + } \\
\text { Maleic an hydrate } \\
\text { grafted PP }\end{array}$ & $80+17+3$ & $\begin{array}{c}\text { Extrusion at } \\
250^{\circ} \mathrm{c}\end{array}$ \\
\hline 3 & $\begin{array}{c}\text { PPCP +SGPPCP + } \\
\text { Maleic an hydrate } \\
\text { grafted PP }\end{array}$ & $\begin{array}{c}\text { Extrusion at } \\
250^{\circ} \mathrm{c}\end{array}$ \\
\hline
\end{tabular}

PPCP

SGF PPCP

Maleic anhydrate $\quad-$ compatibilizer (Maleic anhydrate grafted PP for better bonding between PPCP)

Based on the need for enhanced property, these percentages were decided and also considered the density and impact 


\section{International Journal of Science and Research (IJSR) \\ ISSN (Online): 2319-7064}

Index Copernicus Value (2013): 6.14 | Impact Factor (2015): 6.391

strength of the base material. The more the additive material is added the more is the density and the impact strength gets affected further.

\section{Results}

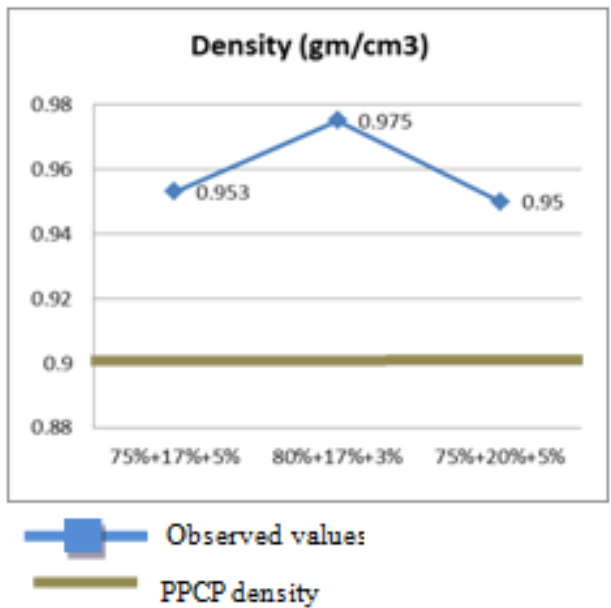

Figure 2: Influence of SGF PP on density of the material

The density of the material increased compared to PPCP. The surface nature became rough and the glossy nature was reduced. Among the formulation studies, the second formulation showed higher density and also low tensile strength to flexural modulus. In that formulation low quantity of glass fibre material and bonding materials (Compatibilizer) are present. This shows that if bonding is also not good there will be variations in weight and other properties.

\section{Mechanical Properties:}

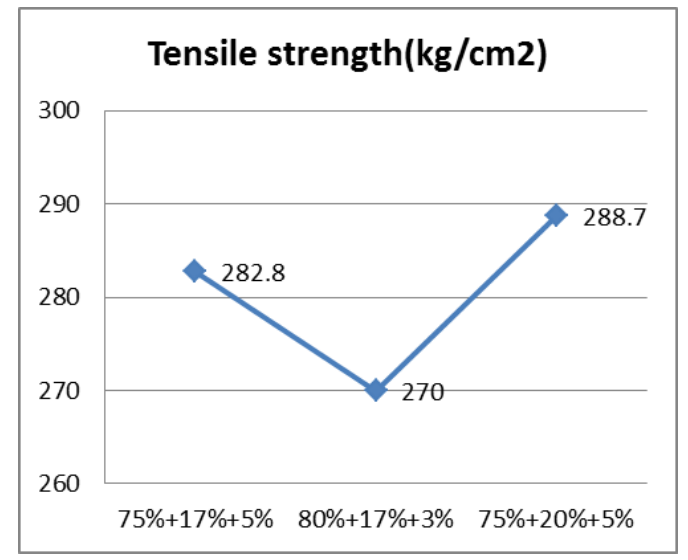

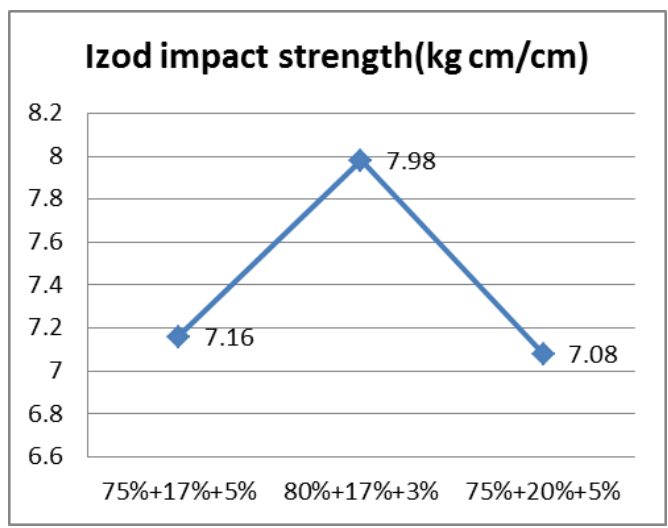

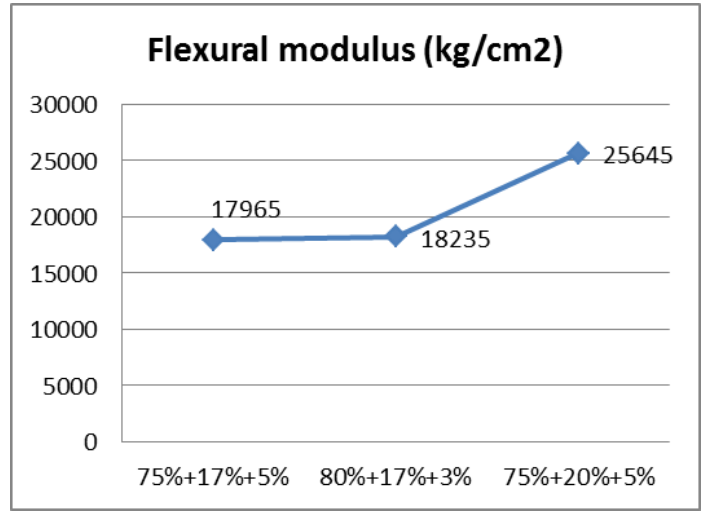

Figure 3: Influence of SGF PP on Mechanical properties of the material

The blend of Glass fibre material in PP, The mechanical properties have improved significantly and the dimensional stability of the specimens appeared good. By this it can be said that the amorphous nature of the material has increased in base material. There is a drastic improvement in tensile strength and flexural modulus from fig 3 but at the cost of impact on impact strength. Of all the three formulations, Third formulation has shown good improvement because of high glass fibre content and bonding agent in it. From this it can be said that bonding plays a crucial role as well as reinforcing agent.

\subsection{Glass Bubble Material}

Coming to the GB powder, these are hallow glass spheres which are manufactured out of soda lime borosilicate glass in different diameters ranging from $15-65 \mu \mathrm{m}$ with densities ranging from $0.15 \mathrm{gm} / \mathrm{cc}$ to $0.60 \mathrm{gm} / \mathrm{cc}$ 


\section{International Journal of Science and Research (IJSR) \\ ISSN (Online): 2319-7064}

Index Copernicus Value (2013): 6.14 | Impact Factor (2015): 6.391

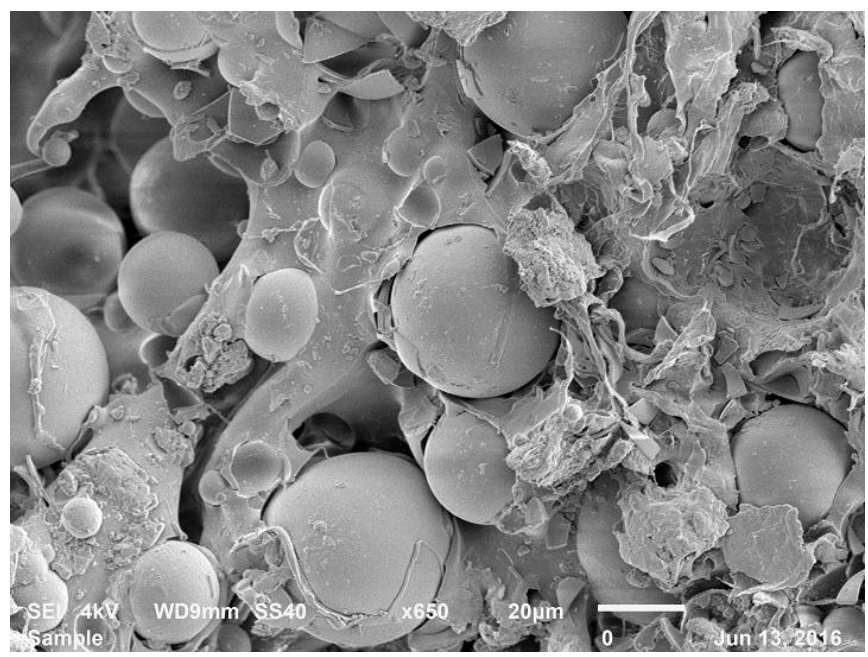

Figure 4: SEM view GB with PPCP

Though these GBs are less in weight, mechanical properties are also low compared to PPCP or SGFPP. Incorporating this in PPCP in certain amount reduces the weight at the cost of certain mechanical properties. But at the same time, it not only reduces the weight, it offers other advantages like good MFI and reduced warpage [10]. As weight reduction is one of the important factors considered in present market, it is being tested in the present study.

The additive along with PPCP was extruded in certain percentage and made into pellets for easy use in injection molding machine. The GB material in PP easily gets dispersed in molten polymer material. Though hallow in nature, it has a very good pressure and temperature with standing capacity during injection process.

\subsubsection{GB material compounding}

This material compounding and process followed for compounding are as per the below table. As the processing temperature of this material is also as same as PPCP so they can be processed in injection molding machine without changing the process parameters.

Table 5: The following table shows the compounding percentages and process followed

\begin{tabular}{|c|c|c|c|}
\hline $\begin{array}{c}\text { Sl. } \\
\text { No }\end{array}$ & $\begin{array}{c}\text { Materials } \\
\text { formulated }\end{array}$ & $\begin{array}{c}\text { Percentage of } \\
\text { material composition } \\
\text { (For 100\%) }\end{array}$ & Process followed \\
\hline 1 & PPCP +GB & $95+5$ & Direct injection mold mixing \\
\hline 2 & PPCP +GB & $90+10$ & Direct injection mold mixing \\
\hline 3 & PPCP +GB & $85+15$ & Direct injection mold mixing \\
\hline
\end{tabular}

\subsubsection{Results}

The above percentages are considered taking account of density and mechanical properties of the direct material. There is no compatibilizer used because of its spherical shape by which it gets distributed easily in the material.

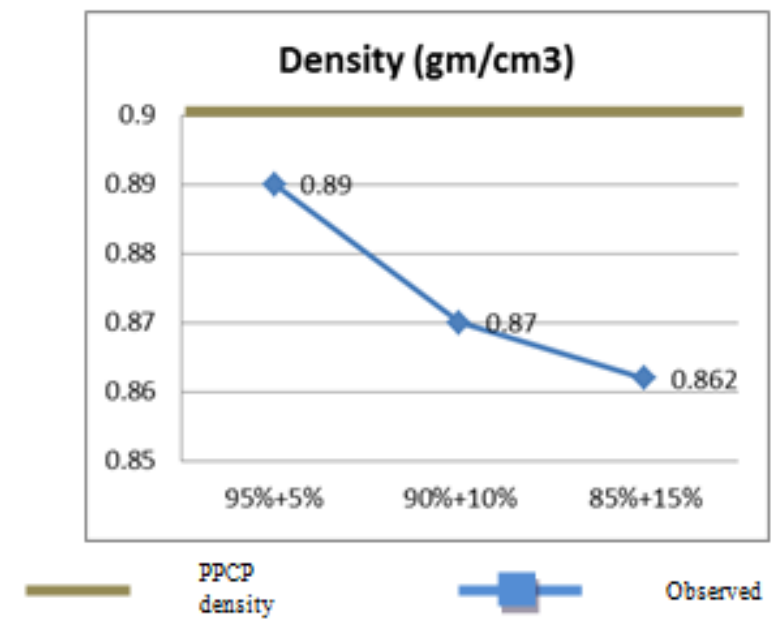

Figure 5: Influence of GB on density of the material

As said, Density of the material reduced by the addition of GB material. The results are in agreeable with earlier studies by Baris Yalein (11) .The material gets joined in between PPCP molecules giving raise to low density material. The more the additive added, the more the drop in density of the material.
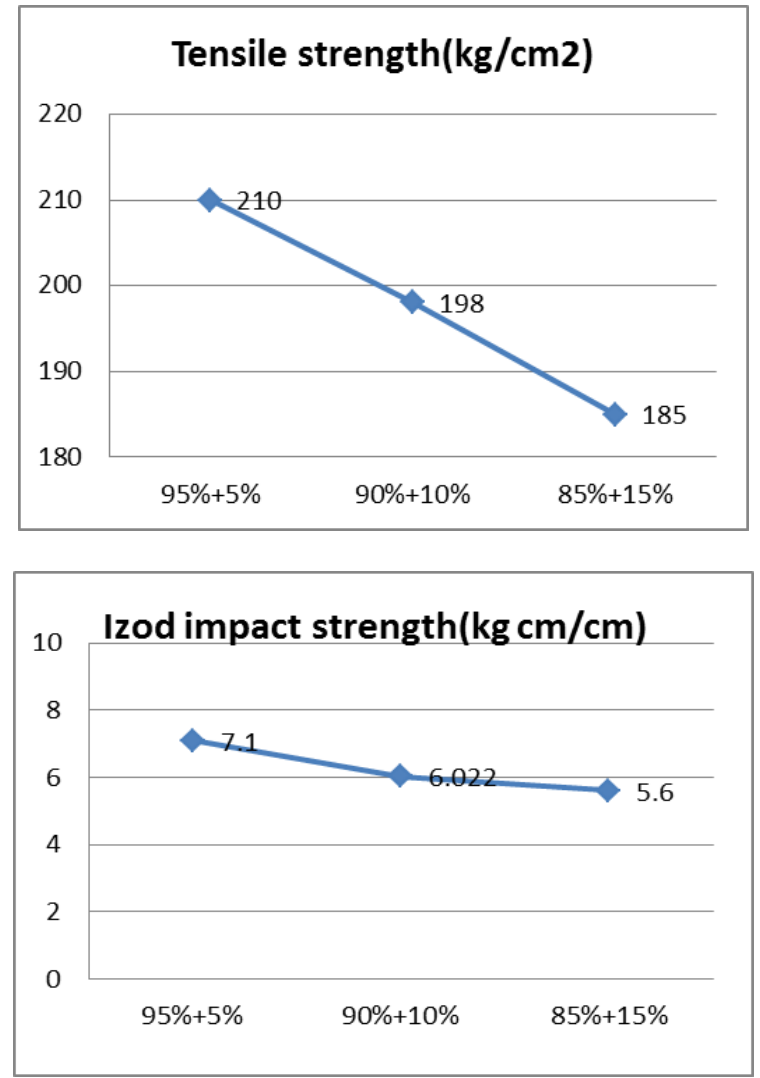


\section{International Journal of Science and Research (IJSR) \\ ISSN (Online): 2319-7064}

Index Copernicus Value (2013): 6.14 | Impact Factor (2015): 6.391

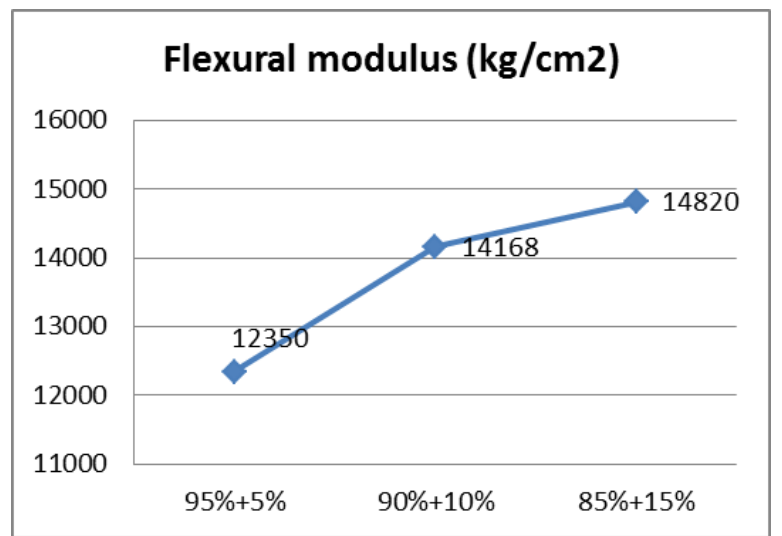

Figure 6: Influence of GB on Mechanical properties of the material

It is observed from fig 6 that there is a fall in tensile strength and impact strength by increasing percentage of GB material in PPCP (base material). The flexural modulus of the material has shown improvement because of this bubble filled structure. This bubble filled structure showed low bending tendency which opposes the force being applied on it. From the graphs it can be observed that the flexural modulus of $3^{\text {rd }}$ formulation is higher and the impact strength is reduced. The second formulation is at moderate level in all the properties.

\subsection{Material combination trail}

As from the above results, the combination has been finalized.

Table 6: The following table shows the compounding percentages and process followed.

\begin{tabular}{|c|c|c|c|}
\hline $\begin{array}{c}\text { Sl. } \\
\text { No }\end{array}$ & Materials formulated & $\begin{array}{c}\text { Percentage of material } \\
\text { composition (For } \\
100 \%)\end{array}$ & $\begin{array}{c}\text { Process } \\
\text { followed }\end{array}$ \\
\hline 1 & $\begin{array}{c}\text { PPCP +SGFPP +GB + } \\
\text { Maleic an hydrate } \\
\text { grafted PP }\end{array}$ & $65 \%+20 \%+10 \%+5 \%$ & $\begin{array}{c}\text { By } \\
\text { Extrusion at } \\
250^{\circ} \mathrm{c}\end{array}$ \\
\hline
\end{tabular}

The motto behind selecting this combination is to even all the properties. In the above materials, one will advance tensile strength and the other advances density. In order to compromise all, these materials have been combined in the desired percentages and have been tried.

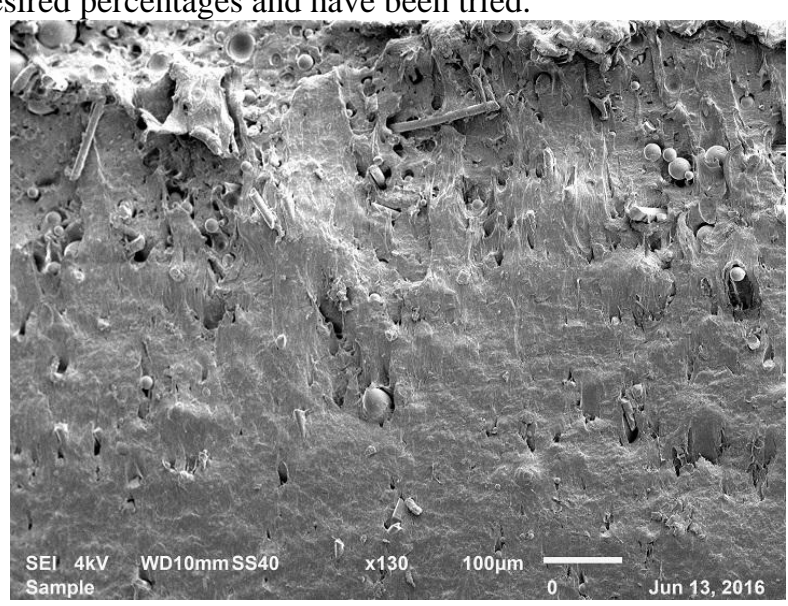

Figure 7: SEM view of both GB and SGF with PPCP
Table 7: The following table shows mechanical properties percentages and process followed

\begin{tabular}{|c|c|c|c|c|}
\hline Sample material & $\begin{array}{c}\text { Density } \\
(\mathrm{gm} . / \mathrm{cc})\end{array}$ & $\begin{array}{c}\text { Tensile } \\
\text { strength } \\
(\mathrm{kg} / \mathrm{cm} 2)\end{array}$ & $\begin{array}{c}\text { Izod impact } \\
\text { strength }(\mathrm{v}- \\
\text { notch }) \\
\mathrm{Kg} \mathrm{cm} / \mathrm{cm}\end{array}$ & $\begin{array}{c}\text { Flexural } \\
\text { modulus } \\
\mathrm{Kg} / \mathrm{cm} 2\end{array}$ \\
\hline $\begin{array}{c}\text { PPCP+SGFPP+GB+ } \\
\text { Maleic an hydrate } \\
\text { grafted PP }\end{array}$ & 0.94 & 232 & 7.8 & 21107 \\
\hline
\end{tabular}

\section{Remarks from above results}

Based on the above combination (table -6), the results were obtained as mentioned in the above table (Table -7).Density of the material seems to be on the lower side giving rise to a moderate tensile strength and impact strength. But comparing to the PPCP with SGFPP compounding, the tensile strength has reduced and impact strength is at level. And by the density of GB, the composite density is at lower side. Finally coming to flexural modulus, it is on the higher side comparing to PPCP. GB has shown its impact not only on density but also on the mechanical properties.

\section{Conclusion}

Though both the additives are from same family .i.e. Glass based (silica) but both are with different properties. By incorporating SGFPP in PPCP material, it enhanced the mechanical properties except the impact strength but with increase in density. By use of this additive material, brittle nature i.e. amorphous structure of the material get increased there by mechanical properties.

For the GB material, as the material contains hollow spheres which is the key for the low density of the material. By combining this material with PPCP (Base material) density has reduced as per the requirement.

From the above we can conclude that individually each additive has its own advantage. Now combining these two materials and incorporating it in PPCP (Base material) along with Maleic anhydrate PP (Compatibilizer) has resulted in improved flexural modulus of the material. Tensile strength and impact strength aren't disturbed i.e. neither decreased nor increased. And density of the material is same as near to PPCP but far less than SGFPP. By further fine tuning in composition, the density can be much reduced and other mechanical properties can be improved.

\section{References}

[1] Study of talc filled polypropylene- a concept for improving mechanical properties of polypropylene, Shri Kant.

[2] http://www.mineralstech.com/fundamentals-of-flexuralmodulus-or-stiffness-in-reinforced-plastics

[3] Effectiveness of Compatibilizers and Filler on the Performance of the Blends of Thermoplastic Polyurethane/Polyolefins, A Kamble.

[4] Mechanical properties of polypropylene/calcium carbonate Nano composites, Daniel Eiras.

\section{Volume 5 Issue 6, June 2016 www.ijsr.net}


[5] Reinforcing and Toughening of Polypropylene With Self-Assembled Low Molar Mass Additives, O.Sinan Yordem

[6] Effect of short GFs on mechanical properties of polyamide and polypropylene thermoplastic blend composite" by B.V Lingesh

[7] Mechanical Characterization of Thermoplastic ABS /Glass Fibre Reinforced Polymer Matrix Composites by Divakar.H

[8] Mechanical Property of GF Reinforcement Epoxy Composites, Patil Deogonda1, Vijaykumar N Chalwa2

[9] A review on the tensile properties of natural fiber reinforced polymer composites by $\mathrm{H}$. $\mathrm{Ku}$.

[10] http://www.appliancedesign.com/articles/93244-glassbubbles-in-polymer-composites

[11] Polymer Composites with Hollow Glass Microspheres: Processing, Properties and Applications by Baris Yalcin, $\mathrm{PhD}$ 